\title{
The Conflict between and Adjustment of the Upbringing for Children of the Dai Nationality and School Education
}

\author{
Zhongli Guo \\ Yunnan Chinese Language and Culture College, Yunnan Normal University, Kunming, Yunnan, \\ 650092, China
}

1211277803@qq.com

\section{Keywords: Dai nationality; Upbringing of Children; School Education; Conflict; Adjustment}

\begin{abstract}
Based on Huayao Dai the typical cluster of the Dai people in Da Muyu Village, Mosha Town, Yunnan Province, this paper investigates the current status of traditional upbringing for children of the Dai nationality, sorts out the incompatibility between the upbringing for children of the Dai nationality and school education, and proposes to help children of the Dai nationality get better integrated into the modern society based on respecting a nation's traditional culture and measures to realize the self-value and adjust the national development so as to promote the establishment of the awareness of "upbringing conscious", thus providing case reference for the upbringing for children of other nationalities.

The specific research of local education in China is more and more inclined to the appeal of national culture. The application of educational anthropological theory and methods has begun to try to seek cross-cultural dialogue and interpretation, or to provide diversified cases for minority education research in macro or meso or micro. The investigation of upbringing for children of the Dai nationality in this paper is just the cross-cultural dialogue and interpretation based on the appeal of national culture in a bid to seek a more rational adjustment in conflicts.
\end{abstract}

\section{Current Status of Upbringing for Children of the Dai Nationality in Mu Village}

Family upbringing. As the initial upbringing place for children, the upbringing of the Da Muyu Village (hereafter Mu Village) mainly includes nurturing and feeding, survival skills and life ability training, behavioral norms and ethical education. The nurturing and feeding of children of Dai Nationality at $\mathrm{Mu}$ Village are free. The cultivation of survival skills and life skills is mainly completed by parents and grandparents. The most important ones are behavioral norms and ethical education, which mainly include respect for the elderly, industriousness, honesty and trustworthiness, ethics of marriage and love, and ethics of social interaction. They advocate the social orientation of the villages of collective solidarity and mutual assistance; they advocate family ethics of hospitality and virginity. In addition to specific daily behavioral norms for growing individuals, they are more emphasis on the ethical norms of relationships between individuals and individuals, and between individuals and groups; They not only value the positive integration of individuals with the group, but also value the recognition and recognition of their peers or village members, which has become an important reference for their words and deeds in their lives. [3]

Influence of villages. The village plays a very important role in the upbringing of minority children. The village is equivalent to a large family because outside the family is the village, and inside the village are all families. Village education is the extension of family education. From the formation of soci

$\mathrm{Al}$ roles, the social relations in the village help children to recognize their position and form a benign social network to make children socialize smoothly. The aging of the community, the "brothers", and the formation of a kinship network allow children to gain an understanding and experience of themselves and others. Under the influence of blood and geography, children's families are integrated, and the peaceful and stable relationship between villagers makes children's awareness of helping each other. From the perspective of national identity, the dual use of proverbs and Chinese is a major step forward in the integration of $\mathrm{Mu}$ Village Dai nationality into the mainstream culture. The national costumes and ethnic customs of the waist are greatly enhanced to 
enhance the national identity of children. Mu Village Dai nationality's collective concept of merging and avoiding differences has enabled villagers to adhere to the values of collectivism and help to enhance national identity. From the perspective of religious beliefs, Mu Village Dai nationality almost believes in primitive religions, paying special attention to individual concepts and behavioral norms, and affecting children's moral behavior habits and ethical concepts through religious rituals; from the village consolidation, the village culture enhances the identity and cohesiveness of members of the ethnic community. In the long-term development of the village, the formation of a benign social network and the ethical belief of mutual trust and mutual help, the social atmosphere formed by the village itself leads the children outside to return to the village. [4]

School education. The modernity of school education determines that school education in minority areas is to spread mainstream knowledge and help students better adapt to the development needs of socialist modern construction. This is why the school education of Mu Village Dai nationality has not fully adapted to the local ethnic characteristics. Although the Mu Village Dai nationality school has taken many measures to reform, it cannot fundamentally change the situation in which $\mathrm{Mu}$ Village children of the Dai nationality is not satisfactory or unwilling to accept school education. [5]

Influence of other cultures. One is TV media upbringing. Television is the main form of entertainment in the daily life of $\mathrm{Mu}$ Village children. The TV media positively or negatively affects the growth of children, teaches children social cognition, acquires social knowledge information, learns to position self-gender roles, and understands and recognizes media based on their known gender role knowledge in "virtual reality". The image presented in the picture, but it is difficult for children to distinguish the "world in television" from the real world, and thus in this "virtual reality" will inevitably produce various inappropriate social behaviors. The second is the influence in the field of tourism. Every visitor to Mu Village creates "he interacts with me" with $\mathrm{Mu}$ Village children through clothing, language, posture, expression, attitude and other symbols. In the "look" of the tourists "others", Mu Village children are also "seeing" others and becoming an indispensable "watcher" in the tourist field. At the same time, it will also enable children to make diversified changes, such as increased language and communication skills, enriching leisure and entertainment, product awareness and cultural self-confidence, children are very eager to go out of the village and move out. [6]

In short, the upbringing of $\mathrm{Mu}$ Village Children of the Dai nationality from family to village to school and interaction with the "other" has made $\mathrm{Mu}$ Village children's growth and contact with the outside world continue to expand. This led to the cultivation and reconstruction of the traditional culture of Dai nationality. In the process of learning and receiving education, they began to accept different lifestyles, and their ideas and concepts gradually changed, forming a multicultural understanding and recognition, and constantly promoting the socialization of children.

\section{Conflict between the Upbringing for the Dai Children at Mu Village and School Education}

The integration or adaptation of $\mathrm{Mu}$ Village Children of the Dai nationality upbringing and school education is manifested in the following aspects: equal ethics education; consistency of educational expectations; long-term/teacher-student relationship advocating democratic equality; and the two are in a medium of multicultural education. However, different cultures must have two aspects of adaptation and conflict in the process of mutual integration. Similarly, Mu Village Dai nationality's traditional children's upbringing and school education have both a blending side and a conflicting side.

Conflicts between High Expectations and Low Expectations for Education Orientation. The characteristics of school education determine that schools must guide students in accordance with the requirements of basic social values. It is hoped that the students of Dai nationality will study hard, continue to learn smoothly, go out of the village, and win glory for the school and the village. Parents are expected to cooperate with the school to improve their children's academic performance, ensure the rate of enrollment, and so on. However, the living environment of Dai nationality has always been rich in resources, no shortage of food and clothing, leisurely life, 
emphasizing full respect for the natural development of people, and a sense of humanitarian care. Parents of children of the Dai nationality will not force their children to have excellent school performance and good academic performance. Therefore, the educational value orientation shows a peaceful and calm mindset with almost no utilitarian color. These two different levels of educational value will inevitably lead to inevitable conflicts.

The Impact of the "Other Culture" without Screening Conflicts with the Need for School Education to Meet the Physical and Mental Development Needs of Children. The impact of a multicultural environment and atmosphere on children is both positive and negative.TV media not only enriches the entertainment life of children, but also makes it difficult for children to recognize the pros and cons of TV content, which will have a negative impact on children's world outlook, outlook on life and values. The infiltration and taint of the "other culture" is beneficial to the Children of the Dai nationality to absorb the use of modern culture, but on the other hand is not conducive to the protection and inheritance of the national traditional culture. "Other cultures" dump their cultural values to children without screening, so that ignorant children can accept them blindly. Such a lack of screening has created a conflict with the rigid demands of modern school-educated education to meet the physical and mental development needs of children.

Contextual Upbringing Conflicts with Professional Education. Relatively speaking, the goal of specialized education in schools is clearer, more efficient, and more prominent in social functions. Students are more able to adapt to modern society. However, children's traditional upbringing has no specific purpose, no deliberate educational methods, mainly relying on non-formal education, mainly on family and village education, relying on activities, teaching at will, gentle and relaxed. The education of children through long-term national collective behavior habits and traditional customs is far more important than school education. The long-standing traditional upbringing concept influences the acceptance of children's education in a subtle way. Going to school for schooling means to them personally changing their behavior patterns, including eliminating what they have learned in the past and re-learning new knowledge. [7] And this "past" can hardly be changed. Therefore, the children's professional education in the school of the Dai nationality must conflict with the random upbringing.

The Conflict between Traditional Democratic and Loose Upbringing Habits and Parental Management of Teachers. In school education, in the name of "everything is good for students", teachers think they have supreme authority, can represent the school to educate and manage students, let students obey unconditionally, and even punish students arbitrarily. Students can only consciously obey and recognize the authority of teachers unconditionally. Mu Village children of the Dai nationality accepts the loose upbringing that goes with the flow. They advocate democracy, equality, and even some freedom and sloppy, lack of persistence. When faced with the patriarchal management of school teachers, they will be very disgusted and even strongly resist, and the cultural conflict between teachers and students will follow.

Conflicts between Emphasizing the Cultivation of Living Ability and Emphasizing Individualized Growth Evaluation. Educational evaluation concepts often influence the upbringing behavior of children. The villagers' evaluation of "good children" or children's achievements is to have basic living ability, improve the quality of life, and change the existing living conditions. At the same time, more attention is paid to children's ethics and morality, and they maintain a natural attitude towards children's school performance. This kind of evaluation is consistent with the modern educational concept, but the parents of Mu Village Dai nationality do not pay enough attention to the systematic study of modern mainstream cultural knowledge, which is not conducive to the formation of comprehensive development talents. It is difficult to cultivate talents who truly have ideals, qualities, and quality that meet the needs of society. The lack of mainstream cultural knowledge may make children lose their advantage in future competition, which in turn affects children's future employment and life. Such a vicious circle will affect the healthy development of students themselves, villages and even modern society. This is in conflict with the evaluation criteria of school education that emphasizes the individualized growth of educators. 


\section{Adjustment of Upbringing for Children of the Dai Nationality in the Conflict with School Education}

The many conflicts between traditional children's upbringing and modern school education have led to the unsatisfactory academic achievements of Children of the Dai nationality, the phenomenon of low initial education rate and limited economic development in ethnic regions. Adaptation is an important way to help Mu Village's children of the Dai nationality adapt to modern school education and realize national modernization.

Create Momentum to Boost Self-Adjustment with Policy. The first is to influence its upbringing concept through economic means. Help them to actively respond to poverty alleviation plans of all levels of government, and rely on favorable policies. On the basis of protecting their own traditional national culture, they consciously overcome the limitations of the traditional upbringing concept, overcome the local concept, and give full play to their own market competitive vitality. The second is to use education and publicity. The school may organize parent conferences by the school leaders or related teachers. From time to time, foreign researchers will hold educational lectures for the villagers, but it is necessary to pay attention to the form of flexibility, focus, specificity and practicality. Using case or policy explanations to help villagers understand the development of society and modern educational concepts so as to exert the influence subtly. Third, policy inclination and role model complement each other. The government can formulate some special policies and policies for local minority education to help solve economic difficulties, pay attention to and actually improve the employment problems of students, and enhance parents' investment awareness and determination in school education. At the same time, the government can use the policy to create a model role to help the Children of the Dai nationality get the job opportunities after completing the education, so that they become role models for local children in terms of quantity and quality. This shifts direct policy incentives into indirect policy support, allowing villagers to feel the realization of self-worth.

Optimize School Education for the Minority.Adjustment of School Education Goals in Ethnic Areas.There is a big gap between the training objectives of the new round of curriculum reform and the actual situation of ethnic minorities. We should adjust the talents that are suitable for the development needs of ethnic minority areas as the primary goal. In the formulation of educational goals, we first consider the development of children's social service capabilities, mainly on how to adapt to the requirements of the small-scale society of the nation to open to the outside world, and help students to change the inferiority complex that is difficult to adapt to modern society due to poor self-service capabilities. According to the hobbies and hobbies of the students after entering the school, they will teach them according to their specific needs. After making certain contributions to the economic development of the nation, children will have a sense of self-worth and gain national self-confidence in the expanded foreign exchanges. This will help children to realize the goal of talent development for all-round development of school education step by step.

Reform of School Education Curriculum in Ethnic Areas.Mu Village Dai nationality's education in life and labor skills is closely linked to the future life of children. School education emphasizes the study of scientific and cultural knowledge, paying less attention to the special needs of learners and the learning and inheritance of ethnic minorities to their traditional culture. Children will develop a sense of cultural inferiority in their studies. Children will resist school education in the continuation of culture or habits. They will resist school education and greatly affect their acceptance of mainstream culture education. In this regard, school education should ensure the continuity of the essence of traditional culture of ethnic minorities in the curriculum. Set up courses and disciplines closely related to the production and life of ethnic minorities, learn the traditional production skills that the nation needs, and ensure that even if children drop out of school due to economic or family reasons, the content of school education can still help them to live better. At the same time, students can receive vocational education for ethnic minorities and help minority children develop the skills they need. This allows students to develop their own national economy, achieve self-worth, and understand the knowledge of "his culture" after completing their studies. They learn to view their national culture and other national culture from a multicultural perspective, 
enhance their recognition of the country, and realize the cultivation of national consciousness.

Development and Use of Local Textbooks in School Education System in Ethnic Areas.Rong MA has clearly stated that "the content of the national textbook must include a certain degree of local knowledge about each region and ethnic groups". [8] As a member of the country and a future citizen, both Han and minority students need to understand the full range of knowledge of the ethnic communities. From this perspective, it is unreasonable that schools in ethnic minority areas adopt the same syllabus and teaching materials as the urban ones, which rarely consider the particularity of minority students. After entering the school, minority students found that the school textbooks did not have the content of their own national culture, and it was difficult to realize the self-construction and identity of the nation. Therefore, although there have been ideas for the development of local textbooks for many years, the actual contradiction of who develops, how to develop, whether to use it after development, and economic support is always unsatisfactory. However, it is necessary to supplement and develop the local curriculum or teaching materials in accordance with the national curriculum system. It is also necessary to make great efforts to invest in the development. Moreover, the "local" curriculum or the local textbooks must not be put on the shelves. This is an important issue that should be considered and focused on school education in ethnic minority areas.

Use Bilingual Teaching to Optimize School Education. Language problems are the biggest problem faced by minority students when they receive school education. The learning outcomes caused by the differences in the local language of the local Dai nationality are very obvious. Therefore, bilingual education should be a good solution to solve the problem. There are very few teachers who have bilingual and formal qualifications in local schools. Even other ethnic teachers who have some slang cannot understand the needs and expectations of minority children. We should try to train our national teachers, try to train the outstanding members of ethnic minorities in vocational education, help them learn the basic skills of teachers, and prepare for becoming a qualified minority and even bilingual teachers. On the other hand, many bilingual teachers do not understand the true meaning of bilingual education, and it is difficult to truly achieve the ultimate goal of bilingual education. Therefore, school education should focus on improving the quality of bilingual education, improving the Chinese language ability of minority students, reducing learning disabilities caused by different language types, allowing ethnic students to adapt to school life as soon as possible, and enhancing national self-confidence and pride. At the same time, the common development of tradition and modernity is realized.

Transforming the Role of School Teachers in Ethnic Areas. Han teachers in schools in ethnic areas have more advantages in the dissemination of scientific and cultural knowledge, and are good at systematic knowledge transfer; Minority teachers have an advantage in understanding the national psychology of minority students and understand the psychological characteristics and national customs of students' learning. Both types of teachers have their own strengths and weaknesses. According to this, teachers need to play different roles, need to change their roles, and need to change from communicators of mainstream culture to practitioners of multiculturalism. This is an urgent need for the reality of school education. In minority areas, both Han teachers and minority teachers should be the coordinator of traditional national culture and modern school education to help students adapt to the demands of modern society for learners in school education. And in the modern education, the ethnic culture of ethnic minority students is passed down. On the basis of national identity, we will walk out of the small circle and stand in a broader world to look at different cultures and achieve coordinated development of multiculturalism. On the basis of national identity, we will walk out of the small circle and stand in a broader world to look at different cultures and achieve coordinated development of multiculturalism.

\section{Acknowledgements}

This paper is a phased outcome of the project "Upbringing for Children of the Dai Nationality" (15FJK003), sponsored by the National Social Science Foundation. 


\section{References}

[1] Zhongli Guo. Balance and Outlook: A Study of the Upbringing for Children of the Dai Nationality in $\mathrm{Mu}$ Village in terms of interaction theory [D]. Kunming: Yunnan University, 2012: 36.

[2] Zhongli Guo. Balance and Outlook: A Study of the Upbringing for Children of the Dai Nationality in $\mathrm{Mu}$ Village in terms of interaction theory [D]. Kunming: Yunnan University, 2012: 68 .

[3] Zhongli Guo. Balance and Outlook: A Study of the Upbringing for Children of the Dai Nationality in $\mathrm{Mu}$ Village in terms of interaction theory [D]. Kunming: Yunnan University, 2012: 126.

[4] Zhongli Guo. Balance and Outlook: A Study of the Upbringing for Children of the Dai Nationality in $\mathrm{Mu}$ Village in terms of interaction theory [D]. Kunming: Yunnan University, 2012: 191.

[5] Xiaoyan Wang. Problems and Thoughts on Modern Education of Lahu Nationality in Hekai Mountainous Area of Menghai County, Xishuangbanna [J]. Contemporary Education and Culture, 2010(6): 54.

[6] Rong Ma. How to Think About the Construction of Local Textbooks in Minority Areas in China, Peking University Education Review, January 2010, Volume 8, Number 1. 